\title{
Interlocuções do Projeto ético- político do Serviço Social brasileiro com o mundo: entrevista com Esther Luíza de Souza Lemos
}

\author{
Maurílio de Castro Matos*
}

Entrevista com Esther Luíza de Souza Lemos, assistente social graduada pela UNIOESTE (Universidade Estadual do Oeste do Paraná), mestra e doutora em Serviço Social, respectivamente pela Pontifícia Universidade Católica de São Paulo e Universidade Federal do Rio de Janeiro, e pós-doutora em Política Social pela Universidade de Brasília. Desde 1994 leciona no Curso de Serviço Social da UNIOESTE, com inserção na graduação e pós-graduação stricto senso. Tem tido uma intensa participação nos debates da profissão e na sua organização política, com destaque para sua participação no Conjunto CFESS-CRESS. Foi conselheira do CFESS nas gestões "Tempo de luta e resistência" (2011-2014) e "Tecendo na luta a manhã desejada" (2014-2017), tendo coordenado a comissão de relações internacionais nas duas gestões e sendo vice-presidente da entidade na segunda gestão. Participou do Comitê Mercosul de Serviço Social e da sua transformação em Coordenação do Comitê Latinoamericano e Caribenho de Organizações Profissionais de Trabalho Social/Serviço Social (COLACATS), sendo sua primeira coordenadora até 2017, quando se encerrou a gestão.

*Professor Adjunto da Faculdade de Serviço Social da Universidade do Estado do Rio de Janeiro (FSS/UERJ). Assistente Social da Secretaria Municipal de Saúde de Duque de Caxias/RJ. Doutor em Serviço Social (PUC/SP). Foi conselheiro do CFESS nas gestões "Tempo de luta e resistência" (2011-2014) e "Tecendo na luta a manhã desejada" (2014-2017), tendo sido presidente na segunda gestão. Correspondência: FSS - UERJ: Rua São Francisco Xavier, 524, sl. 8030-2, bloco D. CEP: 20550-900. Email:<mauriliomatos@gmail.com>. 
EP - Quais os antecedentes históricos da participação do CFESS na articulação internacional?

Podemos dizer que o marco inicial da participação do CFESS na articulação internacional deu-se com a deliberação do seu conselho pleno, após análise cuidadosa, de filiar-se à Internacional Federation Social Workers - IFSW, cuja sigla na língua portuguesa é Federação Internacional de Trabalhadores(as) Sociais - FITS em 1995.

A partir de 1998, o CFESS tem participado das Assembleias Gerais da FITS e dos Congressos Mundiais de Serviço Social, espaços coletivos da categoria que permitem o encontro, intercâmbio e socialização das experiências profissionais e organizativas. Sendo ao mesmo tempo um encontro com a diversidade de concepções sobre a profissão, a participação do CFESS nesse espaço visa construir a articulação e defesa da concepção de Serviço Social a partir da experiência brasileira, respeitando as posições diferentes e mesmo antagônicas. Esse foi sempre um desafio.

A participação nos encontros mundiais permitiu a aproximação com a representação das organizações profissionais latino-americanas e caribenhas, e particularmente, pela aproximação regional, com as organizações dos países do cone sul num momento de enfrentamento do neoliberalismo e de crítica ao projeto do Mercosul.

Neste contexto e com um projeto de crítica à dimensão econômica proposta pelos governos da época, foi criado o Comitê Mercosul de Organizações Profissionais de Trabalho Social/Serviço Social no ano de 1996. Seu objetivo era fortalecer as organizações a partir do cone sul e incidir com organicidade no debate internacional. O Comitê Mercosul reunia-se duas vezes ao ano e passou a construir um campo de articulação latinoamericana em torno dos temas demandados pela FITS bem como a emitir posicionamentos a partir de sua inserção na conjuntura regional. Na experiência do Comitê Mercosul a participação da Assistente Social Elaine Behring e da gestão do CFESS à época foi muito importante.

Ao mesmo tempo, o CFESS ao longo das últimas 8 (oito) gestões manteve sua participação compondo a representação da FITS - América Latina e Caribe com as seguintes conselheiras como vogais no cargo da vice-presidência na região: Valdete de Barros (1998 - 2002), Joaquina Barata Teixeira (2004 - 2008) e Ivanete Boschetti (2008 - 2012).

Ao longo destes 22 anos, fazendo um caminho de volta, considero cinco grandes e importantes contribuições do Serviço Social brasileiro no âmbito das relações internacionais. A primeira refere-se ao voto contrário à aprovação da Definição de Serviço Social na assembleia geral de Montreal em 2000. Deste processo, depois de 10 anos, na assembleia geral de Hong Kong, aprovou-se a realização de um Workshop para rediscutir a Definição sendo o mesmo sediado pelo Brasil em 2012. 


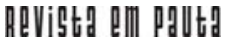

\} INTERLOCUÇÕES DO PROJETO ÉTICO-POLÍTICO DO SERVIÇO SOCIAL - MATOS, M. C. \}

DOI: $10.12957 /$ REP. 2017.32728

A segunda refere-se à contribuição brasileira no debate e na definição de princípios éticos comuns para os países que integravam o Comitê Mercosul - Argentina, Brasil, Chile, Paraguai e Uruguai. O acúmulo da discussão e construção coletiva culminou com a aprovação em 2000, em Seminário realizado na cidade de Montevideo - Uruguai, dos princípios ético-políticos para atuação do/a assistente social nestes países.

O terceiro marco que destaco foi a incansável articulação para trazer a realização do Congresso Mundial de Serviço Social para a América Latina. No âmbito das relações internacionais este foi o momento de maior expressão, capacidade organizativa e investimento da categoria no âmbito internacional. O trabalho de nossas representantes à época, e aqui destaco Joaquina Barata e Ivanete Boschetti, juntamente com as respectivas gestões do conjunto CFESS/CRESS, viabilizou a realização do $19^{\circ}$ Congresso Mundial de Serviço Social da FITS em 2008 na cidade de Salvador. A temática foi "O desafio de concretizar direitos numa sociedade globalizada e desigual", contando com a representação de 47 países e 2.704 profissionais e estudantes de serviço social, sendo a maior conferência mundial realizada pela FITS até então! O quarto aspecto que destaco foi a ampliação da articulação internacional na região, nascida e consolidada com o Comitê Mercosul com 5 países. Desta experiência e capacidade de agregar novos países no espírito de integração latino-americana, em 2013 foi criado o Comitê Latinoamericano e Caribenho de Organizações Profissionais de Trabalho Social/Serviço Social - COLACATS. A adesão de mais países ao processo de articulação, que foi sendo construída desde 1996 com o Comitê Mercosul, permitiu fortalecer a voz e o voto da representação latino-americana e caribenha no âmbito mundial. Este é um aspecto fundamental, pois a correlação de forças na assembleia geral da FITS é desigual e possui a hegemonia dos países europeus. Ao longo dos últimos anos ocorreu um processo de ampliação da filiação à FITS, porém a concentração da direção permanece europeia por possuir o maior número de países filiados. A votação se dá por país cuja representação é feita pela organização profissional nacional filiada e em dia com a anuidade. Em 2014, pela primeira vez, nossa região apresentou candidatura à presidência da FITS com o nome do então presidente da Associação de Assistentes Sociais do Uruguai - ADASU, Rodolfo Martinez, perdendo apenas por 4 (quatro) votos.

O quinto aspecto a ser destacado e que considero uma vitória recente da articulação latino-americana no âmbito mundial foi a incidência junto à comissão organizadora e a realização do convite à Assistente Social e Profa. Dra. Marilda Vilella lamamoto, docente aqui da UERJ, como conferencista principal na Conferência Mundial de Serviço Social de Melbourne - Austrália em 2014. Ter uma profissional latino-americana falando em português e ter sua conferência traduzida para cinco idiomas (inglês, espanhol, francês, mandarim e coreano) foi uma grande vitória tanto pelo reconhecimento e valorização de uma intelectual brasileira quanto pela publicização da con- 


\section{hevistg all paUtg}

\} INTERLOCUÇÕES DO PROJETO ÉTICO-POLÍTICO DO SERVIÇO SOCIAL - MATOS, M. C. \}

DOI: $10.12957 /$ REP.2017.32728

cepção de profissão que temos defendido ao longo destes anos. O restante do mundo pouco conhece o que temos construído como profissão e esta foi uma oportunidade significativa de nossa voz ser ouvida.

Penso que rapidamente estes marcos expressam os antecedentes históricos da participação do CFESS no âmbito as relações internacionais destacando a necessária persistência, capacidade de diálogo e trabalho coletivo neste âmbito que envolve diversidade cultural, diferentes concepções e trajetórias profissionais.

EP - Quais os principais legados do Comitê Mercosul para a articulação da região?

Considero que o grande legado do Comitê Mercosul foi a iniciativa de, a partir do cone sul e de um projeto comum de profissão, construir uma interlocução que fosse representativa da região e defendê-la no âmbito mundial estabelecendo o diálogo com todos os países. Este foi fundamental no apoio que o Brasil recebeu quando se propôs sediar a Conferência Mundial de 2008. Desta capacidade de articulação e construção coletiva o marco comum foi a aprovação, no ano de 2000, de princípios ético-políticos comuns entre Argentina, Brasil, Chile, Paraguai e Uruguai, inaugurando uma base comum na concepção da profissão. De lá em diante a perspectiva foi ampliar o número de países da América Latina e Caribe.

EP - Você participou da organização do workshop da Definição de Serviço Social, que balanço você faz deste encontro realizado aqui na UERJ?

O workshop expressou o êxito do trabalho coletivo e articulado! Aqui no Brasil trabalhamos em um Grupo de Trabalho ampliado com a participação de representantes do CFESS, da ABEPSS, da ENESSO e de pesquisadoras da área na assessoria. O trabalho deste GT resultou em um documento preliminar que foi finalizado em 13 de agosto de 2011 com a participação da vice-presidente da FITS-ALC à época, Laura Acotto (Argentina). O CFESS traduziu este documento para o espanhol e o distribuiu entre os 11 (onze) países que participaram do II Encontro das Organizações Profissionais da FITS que ocorreu em Mendoza - Argentina no final de agosto de 2011. Lá deliberamos que cada país levaria o documento para ser apreciado nacionalmente, trazendo posição quanto ao seu conteúdo para ser discutido no workshop que seria realizado em 2012.

Este ocorreu dias 8 e 9 de março de 2012, aqui no Rio de Janeiro e contou com a representação de 8 países (Argentina, Brasil, Chile, Costa Rica, Porto Rico, República Dominicana, Nicarágua e Uruguai). Também participaram como convidados internacionais o secretário executivo da FITS, o 


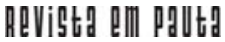

\} INTERLOCUÇÕES DO PROJETO ÉTICO-POLÍTICO DO SERVIÇO SOCIAL - MATOS, M. C. \}

DOI: $10.12957 /$ REP.2017.32728

coordenador da comissão mundial sobre a Definição de Serviço Social na FITS e o ex-presidente da Associação Internacional de Escolas de Trabalho Social - AIETS. Ao total, entre as representações internacionais e nacionais, participaram 83 pessoas incluindo representantes dos CRESS, programas de pós-graduação e estudantes de serviço social.

Foi um evento que teve tradução para o português, espanhol e inglês em um grande exercício de construção de unidade. Traduzimos num texto curto uma definição que pudesse expressar a unidade na diversidade. O resultado pode ser acessado na página do CFESS: http://www.cfess.org.br/arquivos/ definicao-trabalho-social-fits-por-que-revisar.pdf

Um dos maiores resultados foi a incorporação da Definição aprovada no Workshop no Estatuto do COLACATS em 2013.

\section{EP - Como se deu o processo de construção do COLACATS?}

O COLACATS não existiria se não fosse o processo construído no Comitê Mercosul. Este foi dissolvido enquanto nomenclatura, pois sua estrutura foi alterada e novos países foram integrados. Com o acúmulo do Comitê Mercosul, em 29 de maio de 2013 na cidade de Montevideo - Uruguai, foi criado o COLACATS composto naquele momento por 12 países: Argentina, Brasil, Chile, Colômbia, Costa Rica, Cuba, México, Nicarágua, Peru, Porto Rico, República Dominicana e Uruguai.

Todas as organizações discutiram antecipadamente a proposta em seus países e formalizaram a criação assinando a Ata Fundacional e propondo o respectivo Estatuto que foi homologado em 2014. Neste, definiu-se como critério para adesão dos países-membros tanto os princípios ético-políticos aprovados em 2000, quanto a definição de serviço social construída no Workshop sobre a Definição de Serviço Social ocorrido no Rio de Janeiro em 2012.

Atualmente o COLACATS conta com a participação de 15 países, além dos fundadores, integraram-se: El Salvador, Granada e Panamá. Na primeira gestão do COLACATS (2014 - 2017) o CFESS assumiu a coordenação juntamente com o Colégio de Profissionais de Trabalho Social de Porto Rico - CPTSPR.

EP - Neste breve tempo de COLACATS, quais os principais avanços que você identifica?

O primeiro deles foi integrar diferentes países do cone sul, centro américa e caribe construindo uma unidade na concepção e na ação estratégica como América Latina e Caribe, interagindo com as organizações da profissão no mundo. O trabalho coletivo foi fundamental, respeitando as diferenças e 


\section{hevistg all paUtg}

\} INTERLOCUÇÕES DO PROJETO ÉTICO-POLÍTICO DO SERVIÇO SOCIAL - MATOS, M. C. \}

DOI: $10.12957 /$ REP.2017.32728

construindo unidade para que a voz latino-americana fosse ouvida, conhecida e respeitada.

Realizamos 4 Seminários internacionais com a realização e fortalecimento das organizações nacionais: em Santiago - Chile em 2014, em San Juan Porto Rico em 2015, na Cidade do Panamá - Panamá em 2016 e San José Costa Rica em 2017. Todos eles com a representação dos países membros e convite para que demais países se integrassem. Identificar o fortalecimento das organizações nacionais e ao mesmo tempo a ampliação da articulação latino-americana e caribenha é um grande avanço.

Sem dúvida, no tempo mais recente, a realização do workshop sobre a definição de serviço social em 2012 foi determinante para construção desta unidade e inserção coletiva no debate internacional.

A capacidade de articulação consistente juntamente com uma ação política para além de nossa região permitiu que apresentássemos uma candidatura para presidência da FITS em 2014. Esta proposta ganhou a simpatia de demais países, incidindo sobre a hegemonia europeia na direção da FITS, quase ganhando a eleição.

O trabalho articulado com a vice-presidência da FITS para América Latina e Caribe tem sido fundamental na interlocução para além de nossa região. Em 2014 foi eleita a Assistente Social Silvana Martinez, representante da Federação Argentina das Associações Profissionais de Serviço Social FAAPSS.

Outra direção em que atuamos foi a articulação com a Associação Latinoamericana de Caribenha de Ensino e Investigação em Trabalho Social ALAEITS. A nova direção eleita em 2015 em Mazatlan - México, presidida pela Professora Nilsa Burgos da Universidade de Porto Rico, tem participado das reuniões e seminários organizados pelo COLACATS, assinando pronunciamentos conjuntos objetivando uma concepção de profissão que não dissocia trabalho e formação profissionais. Avançamos na articulação entre nossas entidades na América Latina e Caribe.

\section{EP - O que é a FITS e como o CFESS se insere neste espaço?}

A Federação Internacional de Trabalhadores(as) Sociais - FITS, foi criada em 1956 em Munique - Alemanha (a segunda guerra mundial interrompeu a então organização criada em 1928) como organização representativa dos(as) assistentes sociais no âmbito mundial, com natureza privada sem fins lucrativos, mantida pelas organizações nacionais que se filiam livremente, esta se auto sustenta com a anuidade de seus membros. Naquele momento, 12 (doze) países a integraram: Alemanha, Austrália, Bélgica, Canadá, Dinamarca, França, Grécia, Itália, Países Baixos, Suíça, Reino Unido e Estados Unidos. A FITS atualmente é composta por 126 países e em processo de expansão. 


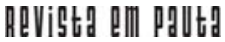

\} INTERLOCUÇÕES DO PROJETO ÉTICO-POLÍTICO DO SERVIÇO SOCIAL - MATOS, M. C. \}

DOI: $10.12957 /$ REP. 2017.32728

No contexto internacional, a FITS é um organismo consultivo do Conselho Econômico e Social (ECOSOC) da ONU e do Fundo das Nações Unidas para a Infância - UNICEF. Ao mesmo tempo trabalha com a Organização Mundial de Saúde - OMS, Escritório do Alto Comissariado da ONU para Refugiados - ACNUR, o Escritório do Alto Comissariado da ONU para os Direitos Humanos - ACNUDH.

O CFESS se insere neste espaço a partir da articulação realizada no COLACATS. Os votos são por países e nas Assembleias Gerais da FITS sentamos perto e nos organizamos como região.

EP - O que o Serviço Social tem a contribuir no debate internacional?

Entendo que tem sido duas as direções nas quais as organizações profissionais tem atuado concomitantemente, tanto na estruturação como profissão, com a definição de serviço social e códigos de ética, quanto na incidência sobre governos e sociedades, especialmente através dos organismos da ONU nas temáticas de políticas para infância, mulheres, envelhecimento, família, população indígena, migrantes, saúde mental, drogas e direitos humanos. O Serviço Social não é uma profissão homogênea e participando da FITS identificamos a predominância de uma concepção conservadora e eurocêntrica. A ampliação e chegada de novos membros na FITS tem ampliado o debate e a disputa pela direção estratégica da forma e conteúdo destas contribuições.

O Serviço Social da América Latina e Caribe tem uma grande contribuição a partir do que temos realizado em nossos países no enfrentamento à barbárie gerada pelo capitalismo contemporâneo, nossa herança colonial e patriarcal. Na efetivação do projeto ético-político profissional, os/as assistentes sociais denunciam e ao mesmo tempo intervém nas contradições que chegam como demandas pro Serviço Social, fruto das expressões da "questão social". A crítica que temos construído nos respectivos países precisa ganhar as ruas e neste sentido as organizações nacionais podem promover intercâmbios na perspectiva de adensar as forças e dar visibilidade a elas.

EP - Em que o contato com a internacionalização pode contribuir com o Serviço Social brasileiro?

A internacionalização coloca novos desafios para o Serviço Social brasileiro, particularmente no intercâmbio da pesquisa. Podemos avançar coletivamente e internacionalmente na pesquisa sobre o próprio serviço social, colocando-o como objeto de estudo e sobre as determinações particulares do capitalismo contemporâneo. A conjuntura econômica regressiva, ao mesmo tempo em que não favorece a interlocução tendo 


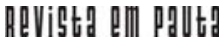

\} INTERLOCUÇÕES DO PROJETO ÉTICO-POLÍTICO DO SERVIÇO SOCIAL - MATOS, M. C. \}

DOI: $10.12957 / R E P .2017 .32728$

vista os custos e investimentos necessários para o financiamento da participação em atividades internacionais, também exige maior capacidade de articulação permitindo que ampliemos o diálogo com outras culturas e trajetórias profissionais.

DOI: 10.12957/rep.2017.32728

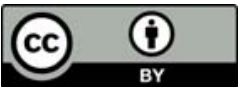

A Revista Em Pauta: Teoria Social e Realidade Contemporânea está licenciada com uma Licença Creative Commons Atribuição 4.0 Internacional.

EM PAUTA, Rio de Janeiro - 20 Semestre de 2017 - n. 40, v. 15, p. 349 - 356 